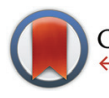

CrossMark

Cite this: Inorg. Chem. Front., 2016, 3, 558

DOI: 10.1039/c6qi90012g

rsc.li/frontiers-inorganic

\section{Correction: A new methylviologen-templated zinc gallophosphate zeolite with photo-/ thermochromism, fluorescent and photoelectric properties}

\author{
Chunyao Tao, Junbiao Wu, Yan Yan, Chao Shi and Jiyang Li*
}

Correction for 'A new methylviologen-templated zinc gallophosphate zeolite with photo-/thermochromism, fluorescent and photoelectric properties' by Chunyao Tao, et al., Inorg. Chem. Front., 2016, DOI: $10.1039 / c 5 q i 00283 d$.

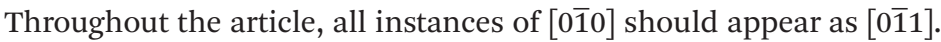

The Royal Society of Chemistry apologises for these errors and any consequent inconvenience to authors and readers. 